\title{
Out of Bounds: The Message Is the Medium
}

Patrick Rafferty

For me, a lowly prison scribe, to try to transpose the timely aphorism 1 uttered by one of Canada's leading scholars (recently deceased) may seem a little pretentious, if not totally antithetical. But I know in my mind that Marshall McLuhan, who was routinely called a media guru and the oracle of the electric age, would have welcomed contrary insight from anyone with the temerity to tinker with his favorite toys-words. McLuhan's brash statement that "the medium is the message" turned the world of communications on its head, as did many of his theories - a term he disliked. From what I understand, he preferred to call his concepts a "probe" into the collective consciousness surrounding the art and science of communication: a probe designed to stir controversy and stimulate dialogue, a process that inevitably leads to the development of character and mental powers, which is how the dictionary defines education.

Herbert Marshall McLuhan was born in Edmonton, Alberta, on July 21, 1911. Several years later his family moved to Winnipeg, Manitoba, where he grew up while receiving a modest grade school education. He enrolled at the University of Manitoba with the intent of becoming an engineer, but quickly switched to English literature. He was awarded his B.A. degree at Manitoba in 1933, and his M.A. degree in 1934. He studied overseas at Trinity Hall in Cambridge University, taking another B.A. degree in 1936, another M.A. in 1940, and his $\mathrm{Ph} . \mathrm{D}$. in 1942, in the respective fields of medieval education, Renaissance literature, and Elizabethan rhetoric. Upon his return to North America, he taught at the University of Wisconsin and St. Louis University, and then at Assumption University in Windsor, Ontario. Later, he taught at the University of Toronto, where he was named a full professor in 1952 . He became the director of the University of Toronto's Centre for Culture and Technology in 1963. He was appointed to the Albert Schweitzer Chair in Humanities at Fordham University in New York City in December of 1966, and was a fellow of the Royal Society of Canada, and held an honorary doctorate from the University of Windsor. McLuhan has written eighteen major books and countless articles.

However, I believe the message in Out of Bounds magazine is the medium through which prison reform can be realized. In addition, it is the medium through which personal reform can be realized for all of those who grace its 
pages, read its message, or are involved in its production. Significantly, it can be argued that personal reform precedes prison reform in both time and importance. Out of Bounds is the quarterly published by Pithy Penal Press at William Head Institution, British Columbia. Over the eight-plus years that I have been involved, I have witnessed considerable reform, or what I prefer to call growth, in the attitude and ability of many of the 'inside'contributors to the magazine. Thankfully, my involvement in this literary endeavor has initiated quite a bit of positive growth of my own.

This growth, or reform-what Correctional Service Canada is wont to take credit for and call rehabilitation -is the cumulative effect of alterations in attributes and opportunities. Without doubt, the singular most significant altered attribute would have to be higher self-esteem and its concomitant increase in feelings of self-worth that individuals experience from having their writing or art published.

And perhaps the most ostensive opportunity a prison publication such as ours provides is a venue for disseminating discontent, an expedience that can actually alleviate some of the frustrations from not having a voice. These frustrations, if they are not expressed in an appropriate manner, can lead to destructive thoughts and aberrant behavior. Ideally, a message is the means to an end. Stated differently, the message is the medium. More specifically, the message in Out of Bounds is the medium for change. This change can encompass thoughts, feelings, attitudes, and behaviors; but more importantly, it heralds enlightenment. Education is the ultimate end. Producing a prison publication is an educational experience bar none. And in this case, as with most prison publications, the enterprise is prisoner inspired, owned, and operated.

Not surprisingly, there is some applicability to McLuhan's utterings with respect to our tiny tome. Although the ideas inherent to the content of a medium must take precedence over its form, that does not necessarily mean its structure and design are not important. A well-arranged and well-designed printed publication will first attract the eye and then infiltrate the mind. Most publications strive to gain credibility, a complicated task at the best of times. In our case, this effort is compounded by the fact that we are publishing from within a federal penitentiary. Accordingly, by being very particular about our layout and design, and pernickety with our grammar, we earn the confidence of our readers and subsequently impart integrity. Unfortunately, prison publications often have to struggle against society's stereotype of prisoners: that we are 
lesser beings who are dumb yet deceitful. We, as prison writers, editors, and artists can counter this undeserved label by being honest and authentic in our endeavors.

Such a display of veracity does not come unencumbered. Our magazine has a long and storied past. Christened Out of Bounds, a new vessel was launched into the turbulent waters of the penal press on September 4, 1980. The premiere issue had a long name but a short cargo. The masthead read Out of Bounds: William Head Institution Newsletter. The cargo comprised four double-sided $8 \times 11$ inch pages of text and cartoons, all held together by a staple in the upper left-hand corner. Using a typical newsletter format, the founding felons incorporated an atypical logo: a medieval woodcut depicting what I can only construe to be the town fool thumbing his nose at societyvery apropos I might say. That inaugural issue quoted Oscar Wilde from his "Ballad of Reading Gaol" on its front page:

The vilest deeds like poison weeds, Bloom well in prison-air;

It is only what is good in man

That wastes and withers there.

The photocopied newsletter started out as a weekly, but within two months it was cut back to publishing bi-weekly, due to a lack of submissions as well as difficulties in procuring a typewriter, paper, and printing capabilities. Although it is not stated explicitly, it appears the publication's genesis was inspired by the University of Victoria post-secondary degree program taking place at William Head at that time. That same university program generated the inspiration that led to the formation of a prison theatre society in 1981. Now named WhoS, for William Head on Stage, it continues to provide quality theatre for prisoners and the paying public to this day.

Two months later, in January 1981, the newsletter became a monthly, a schedule it stayed with until September 1982, when it became a bi-monthly for one issue and then back to being a monthly in November of that year. By this time the content had increased dramatically. It was up to forty doublesided pages, the title had been trimmed to Out of Bounds Monthly, and the format was fitted with three staples down the left side to give it more of a magazine feel. Gone was the old nose-thumbing logo, replaced by different drawings on each successive cover. The original nose-thumbing attitude, 
however, still ran rife throughout the magazine. In October 1983, the magazine went back to being a bi-monthly and dramatically changed its format. Using 8 $1 / 2 \times 14$-inch paper, folded in half and saddle-stapled, the magazine, now simply titled Out of Bounds, became a $7 \times 81 / 2$ inch booklet with thirty to forty pages. This design change was intended to make reading easier and mailing cheaper. From its inception to the present, the magazine has been sent to interested readers and subscribers in the public domain.

This brief history of the magazine is somewhat sketchy in that I am garnering the information from an incomplete collection of old copies that were generously lent to me by the William Head librarian Kim Remple. Keeping this in mind, it appears that Out of Bounds became a quarterly publication at the beginning of 1990, and then disappeared halfway through 1991. Throughout this long, arduous journey the periodical suffered severe bouts of censorship by the prison administration, and on several occasions lapsed into temporary obscurity due to this censorship and/or a lack of interest on the part of the prisoner publishers.

In 1993, Steve Foote, who had just recently arrived at William Head from Mission Institution, decided to get the magazine up and running again, and I came along - also transferred from Mission-just in time to help him with the "resurrection issue" that came out in June of that year. At that time, we were told that the magazine had not put out an issue for two years, therefore I assume the 1991 issue mentioned above was the last in that line. With its rebirth, we hoped to create a prison publication that was different from all the rest. When I say we, I must give credit where credit is due. A lot of the credit for the longevity of our current uninterrupted publishing run of eight years and counting, and the popularity of Out of Bounds, is due to my friend and mentor Steve Foote. Although Steve only co-edited the magazine with me for one year before moving over to $\mathrm{WHoS}$ to become president of the theatre company, the pertinacious inspiration and positive influence he provided has stayed with me to this day.

We wanted Out of Bounds to be more than just a newsletter, and also to earn greater prestige than the usual "joint newspaper"; therefore, we added magazine to our title and admonished anyone who called it otherwise. We went back to the $81 / 2 \times 11$ inch format, but printed the front and back covers on heavy, canary-colored cover stock that gave the magazine a unique, permanent look and feel. We filled it with an average of forty pages of interesting non-fiction articles, fictional short stories, poetry, and humor; then we bound 
it all with three staples down the left-hand side to keep with the magazine make-up. On our masthead page we permanently placed a quote by Oscar Wilde, without knowing that the premiere issue from 1980 had quoted the illustrious author cum convict. The new quote read,

I need not remind you that mere expression is to an artist the supreme and only mode of life. It is by utterance we live. Of the many, many things for which I have to thank the Governor there is none for which I am more grateful than for his permission to write fully and at as great a length as I desire.

With each new issue we tried to publish an eclectic collection of submissions with the hope that each and every reader would find something that piqued his or her personal interest. We had a copy of Robert Gaucher's article "The Canadian Penal Press: A Documentation and Analysis," published in the Journal of Prisoners on Prisons, from which we learned:

A distinction needs to be made between what I define as "outside directed magazines" and "inside directed or joint magazines." Outside directed magazines are intended to serve as a means of communication with the Canadian public, and therefore feature analysis of contemporary criminal-justice issues and serious prose on the experience of criminalization, incarceration and recidivism. Joint magazines are directed at the population of a particular prison and focus on reporting institutional activities such as sports, social events and club endeavors, and on providing information on new programs and legislation, coming events and internal news. Both provide insight into the perspectives and understanding of prisoners and the everyday experience of prison life in Canada. (Gaucher, 1989, 4)

But with Out of Bounds we amalgamated some of the outside directed aspects with some of the inside directed and then took it one step further, making it a truly unique prison publication. We intermixed the in-depth communication aspect of the outside directed with the inside directed reporting on institutional programs and activities; thus, both prisoners and the public would get an idea of what is going on in our penitentiary. Then we invited and encouraged the public to send us submissions so the communication aspect of the outside directed designation would become a two-way dialogue. Also, we 
canvassed community-based prisoner advocacy groups and organizations devoted to helping prisoners during their incarceration and upon their release. We asked them to send us information so we could regularly publish "outside resources" and thus improve and extend the inside directed aspect. Subsequently, with our hybrid publication we were able to effectively breach the barbed wire that separates the "inside" community from the "outside" one.

Three years into our publishing run we acquired a binding machine. Since the Spring 1996 issue, the black plastic ring binding has added another important cosmetic complement to the magazine's presentation. Then with the Winter 1999 issue we changed editors and completely overhauled the layout and design. We went with white cover-stock, front and back, and put a different photo taken somewhere inside William Head on each successive cover, rather than the prison art that we had previously used. Although we try to maintain a consistent look over long periods of time (on the belief that consistency breeds familiarity, and familiarity ensures a faithful following) wholesale design changes every so often are necessary to keep up with society's changing styles. Consequently, part of the complete overhaul involved changing our original logo and adding another word to the title, becoming Out of Bounds Prison Magazine, a more defined distinction. With the Fall 2000 issue, we changed editors again and went back to putting prison art on the covers due to the substantial urging of both our inside and outside readership.

The educational experience that comes from publishing a prison magazine is truly unique and indescribably valuable. It is far beyond the scope of this particular article to discuss the means and ends of prison pedagogy. It is difficult enough trying to come up with a working definition of education within the custodial milieu. If education involves learning, when you are sentenced to do a semester in the "school of hard knocks" you will learn a difficult lesson every day if you are not careful. The real purpose of education in general has been variously described as individual empowerment, personal development, formal instruction, enlightenment, guidance, and discipline. I prefer to simply call it growth, qualified by the designations spiritual and mental. In my opinion, educational instruction in prison serves a dual purpose. It enables a prisoner to overcome deficiencies such as being illiterate, under-educated, and/or underqualified for trade training. And it serves to prepare a prisoner to better comprehend, and thus benefit from, the rehabilitative programs that he or she will be required to participate in. In contrast, the pattern of education a prisoner- 
initiated enterprise can provide extends well beyond the "correctional" purposes just mentioned.

The tutelage encountered while participating in a prisoner-initiated enterprise such as Out of Bounds speaks more to the psychological and intellectual wellbeing of the participants during their incarceration, as opposed to the illusive specter of rehabilitation that institutional programs cater to. One peculiarity of the "medical model" of corrections, the model most in use today, presupposes that criminals are inflicted with some sort of social ill, and a stint in the penitentiary will somehow (with the aid of countless programs, constant badgering, and a pinch of punishment) miraculously cure this ill so the "rehabilitated" offender can return to society as a law-abiding citizen. Unfortunately, part of this "cure" involves being separated from and scapegoated by society. It involves being labeled, dehumanized, and degraded; it involves the loss of rights, self-respect, and self-determination; but more importantly, it involves the loss of community. I believe that most crime comes about when the perpetrator loses touch with the essence of community and the commonweal essential to its survival.

One of the more important qualities of community that I turned my back on when I entered a criminal lifestyle was the practice of joining together as a group to accomplish common goals for the good of the whole community. Unfortunately, my involvement in crime resulted in me becoming extremely self-centered and selfish, showing little concern for the well being of others. In contrast, my involvement with Out of Bounds has helped alleviate quite a bit of that egoistic attitude and behavior. Participating in prisoner-initiated endeavors contrasts markedly with taking correctional programs. Prisoner-initiated endeavors are voluntary as opposed to mandatory; they concentrate on personal development as opposed to character "correction"; they encourage excellence as opposed to punishing error; and they promote creativity as opposed to enforcing discipline. But most importantly, because prisoner-initiated endeavors impart a strong sense of ownership to their participants, positive feelings of self-esteem and self-determination often result. These are benefits that not only allow for immediate learning but also encourage further exploration, creating an upward-spiraling process of mental and spiritual growth.

There are several complementary rehabilitative features arising from prisonerinitiated endeavors as well. I suppose that is why prison administrators inevitably allow (sometimes even encourage) their existence. Specifically, with a project such as ours, whose primary purpose is communication, the process of enhancing an individual's ability to express his or her accomplishments, 
disappointments, complaints, and concerns in an objective, pro-social manner is at once educational and rehabilitative. Through this process we gain experiential knowledge and a methodology of understanding that assists us in our everyday interaction with both institutional staff and our fellow prisoners.

Experiential learning is an important aspect of any endeavor. We learn best by doing. Didactic programs offered by the Correctional Services Canada (CSC) often fail miserably because they involve less than impartial instructors (forewarned with stereotypes about their students) lecturing to less than enthusiastic participants (usually forced to attend mandatory programs) with a premise that is as controversial as it is demeaning (you are defective, we can fix you). Rehabilitation is more effectively realized when the person who is being rehabilitated perceives that he or she has a stake in that process. With prisoner-initiated projects, that perception is a self-evident outcome. The sense of ownership these endeavors impart upon their participants coalesces with the resultant feelings of self-determination, and together they fuel further learning, dignity, and decorum.

The message in Out of Bounds emanates from the writing and art published in the magazine. Although there can be a different statement expressed in each individual submission, the overall representation is one of contrite hope and realization. By being honest, open, and willing to share our thoughts and feelings with our readers in an authentic manner, we hope to dispel some of the misconceptions that surround prison and prisoners. And by enunciating our own shortcomings alongside the abject failings of the system that we are locked into, we eventually come to the important realization that we can fix ourselves - that we can become rehabilitated a lot easier and more effectively than "be" rehabilitated. We learn that we need to examine and criticize the underlying aberrant attitudes and beliefs that led to our criminal activity with as much rigor and enthusiasm as we expend criticizing the criminal justice system. But in doing so we need not let that system off completely either. Society has to bear some complicity in our social "illness" and learn to prevent that illness rather than try to punish it into remission.

The message in Out of Bounds is one of emancipation. Freedom of speech, in its purest form, is a liberating sentiment. Unfortunately, in prison, freedom of speech is seldom practiced in its purest form, if it is practiced at all. Even under the duress of censorship (whether it be self-imposed to preserve the con-code, or imposed by prison administrators for the "good order of the institution"), the opportunity to voice one's concerns and opinions in a prison 
publication, combined with the educational experience that comes from learning how to write effectively, in an objective manner, speaks to the psychological and intellectual well-being touched upon earlier in this article. If prisoners believe that they can make positive changes to the system as well as to themselves, their incarceration becomes less troublesome in both scope and duration. If we can learn to accomplish things for the common good of our little microcosm of society, a microcosm replete with an abundance of hate, anger, violence, and selfishness, then in a sense we are liberating ourselves from these otherwise negative constraints. If Out of Bounds can nurture an honest sense of altruism in its participants, then it becomes much more than just a prisoner-initiated educational aid and a CSC-cherished rehabilitative tool. It becomes a character-building message, the medium for social change.

On a personal note, I am going to miss working for the magazine when I finally leave this place. The learning aspect of the experience is not the only valuable component. Upon reflection, I keep coming back to the concept of community, and it is not mere coincidence. The Out of Bounds community has made the whole intricate journey worthwhile. To me, our subscribers are not just customers: they are friends. Friends willing to support our cause, willing to listen to our side of the story, willing to hear our voice, a voice that usually falls on deaf ears. And in some cases our subscribers are more than just friends, they are family - literally and figuratively. My family has supported my involvement in the magazine through their encouragement, subscriptions, and donations right from the very beginning. This has a hidden benefit in that I am not very punctual with respect to writing letters, so at least every three months they hear from me through my articles in the magazine.

One thing that really surprised me, and pleases me to no end, is the warmth with which some of our readers invite us into their lives and living rooms. One particular family on the east coast of Canada, who have been subscribers as far back as I can remember, frequently send us letters and newspaper clippings updating us on some of the going-ons with respect to their family and community. They regularly sent us their used postage stamps for our SPCA stamp drive, until the Visiting and Correspondence department of the institution started sending them back, for reasons which are beyond me. They recently suffered a death in their family, and my heart and prayers go out to them, as I somehow feel like an adopted member of that family.

We canvass most of our subscriptions at the bi-annual William Head on Stage productions, quality plays performed in the prison that attract about 150 
people per night each ten-night run. Working the Out of Bounds kiosk that we set up during each production is a highlight of my peripheral involvement with WHoS. I do not socialize much around the prison, and when I do, situation dictates that it is usually with one particularly distinct social sub-class: prisoners. So twice a year I am afforded the frightening pleasure of meeting and greeting a steady stream of diverse personalities from all social classes, collectively known as "the public." I am always grateful when people who are already on our subscription list come to the kiosk and introduce themselves, thereby putting a face to one of the many names we have in our database.

Putting a face on otherwise invisible people (prisoners) is an important mandate of our magazine. By publishing our thoughts and feelings, our hopes and dreams, our accomplishments and failings, as well as the accomplishments and failings of the system we are locked into, we hope to show that we are not just "offenders." We are husbands and fathers, sons and brothers, uncles and nephews, friends, cousins, acquaintances, and in too many cases, long lost relatives. We are a thinking, feeling, breathing part of humanity, albeit somewhat confused and often angered by the complexities of the human social condition and its inevitable failings. Through writing we attempt to make sense of the situation we have landed ourselves in and impart some of that sensibility to the public, as well as to our fellow prisoners.

It always encourages me when I observe, from issue to issue (sometimes from year to year), the positive growth in both ability and attitude of my fellow prison writers and artists. I take pride in assuming that in some small way $O u t$ of Bounds has helped facilitate that growth. The process of taking a small piece of crumpled paper, shyly submitted by a so-called hardened criminal, knowing that he has agonized relentlessly over the writing of that article or poem (in some cases taken a heart-felt risk due to its content), then filltering that submission through the regimen of editing, layout, printing and binding, resulting in what many people believe is one of North America's best prison publications, has its own rewards. For me the reward lies in the look of apprehension, then pride, that emanates from the fellow who made the submission, when I hand him his copy of the finished product and he sees his work in print.

So, as I prepare to leave William Head on day parole, I look forward to taking the Out of Bounds experience with me. In doing so, I encourage all prisoners who are reading this: if you are interested in writing, art, or the process of publishing, get involved with your prison's publication. If you do 
not have a publication, start one. The experience will not only be rewarding, it will be rehabilitative in spite of itself.

\section{REFERENCES}

Gaucher, R. (1989). The Canadian Penal Press: A Documentation and Analysis. Journal of Prisoners on Prisons, 2:1, 3-24.

McLuhan, M. and Quentin, F. (1967). The Medium Is the Message. New York: Random House.

Patrick Rafferty is serving a life sentence for second degree murder with a parole eligibility date of eighteen years. He is currently on day parole in Victoria. He can be reached at 138 Dallas Road, Victoria, BC (Canada) V8V 1A3. 